\title{
The Ebola Crisis in the West African Region: Should It Have Been So Severe?
}

\author{
Ezeakukwu E. Nsoedo \\ Damascus, MD, USA \\ Email: legwoent@yahoo.com
}

Received 22 June 2014; revised 6 October 2014; accepted 20 October 2014

Copyright (C) 2014 by author and Scientific Research Publishing Inc. This work is licensed under the Creative Commons Attribution International License (CC BY). http://creativecommons.org/licenses/by/4.0/

(c) (i) Open Access

\begin{abstract}
A lot of factors magnified the severity of the Ebola outbreak in the West African region. The various regional governments lack the rudimental health care structure and support equipment necessary to checkmate outbreak of infectious diseases like Ebola. The overriding factor that impacted the management of the spread of Ebola disease is the lack of leadership among the various national governments to adapt available health information in the formulation of their national health care policies that should have led the way in training personnel with expertise to manage Ebola disease. The consequence was that when the Ebola outbreak ensued, the region did not have enough qualified personnel to combat the infection, culminating in the massive death casualty of health providers due to the disease. Seeming apathy from the United Nations demonstrated in the big budgetary cut for the World Health Organization's program in the region has a direct impact to the severity of the Ebola outbreak. Hopefully the policy issues identified in this study will unite the member countries in the West African region to have a functional health research laboratory to help diagnose infectious diseases. The international community would do well to provide assistance timely to avoid unnecessary loss of lives and resources in the affected areas, and the entire world will be good for that.
\end{abstract}

\section{Keywords}

Lack of Leadership, Health Policy, Foresight, Budget, Poverty

\section{Introduction}

The entire health care system in the West African region is at various stages of development among the countries that constitute the region. One factor that characterizes all of them is the level of underdevelopment. Giovanni and Germano (1997) whose study on health policy dwelt on mortality among all categories of people in 
the sub Saharan Africa found that ethnic wars and AIDS pandemic were the primary cause of mortality from the 1980 to 1995 [1]. According to Giovanni and Germano "While other new infectious diseases (hepatitis C and D, ebola and other haemorrhage fevers) have emerged, their mortality impact seems, so far, to be modest” (p. 14) [1]. It is important to note that the minor Ebola outbreak was outside the West African region during the authors' study.

According to Waterman (1999) the Ebola virus first emerged in Africa in 1976 in Zaire (now Democratic Republic of Congo) and Sudan, and it was named after Ebola River in Zaire [2]. Waterman noted there were other known Ebola infections, Ebola Reston in Virginia and Ebola Mindanao in the Philippines [2]. There were other sporadic outbreaks in Africa with a limited number of human infection under 400, even though with high mortality rate of $53 \%$, with $88 \%$ being the highest mortality rate (Waterman, 1999) [2]. There was no question that AIDS pandemic was more of a dreadful prospect for the inhabitants of the sub-Saharan region in the long term (Giovanni \& Germano, 1997) [1], but AIDS seemed to have stabilized considerably, perhaps due to investment of resources to combat the disease. The Avert (2012) reported "there were 1.2 million deaths due to AIDS in 2011 compared to 1.8 million in 2005. Almost 70\% of people living with HIV worldwide live in sub-Saharan Africa" (para 2) [3].

Report indicated that the previous outbreak of Ebola disease in the past had been outside the West African region with minimal death toll compared to the present outbreak which was taking place in the region, mainly in Liberia and some of the affected countries. Therefore, it becomes imperative to consider some of the variables that may have contributed to what is now shaping up to be an epidemic of a higher proportion.

The previous Ebola outbreaks in Sudan, Zaire (Democratic Republic of Congo), Uganda were all contained within a short period of time that ensured the safety of the larger population with minimal fatalities. There is need to understand why the outbreak in the West African Region seems out of control. The questions to address are:

1) How did the Ebola outbreak in the West African region become so uncontrollable?

2) Did the affected countries pursue the containment of the Ebola outbreak with known approach used in the previous outbreaks outside the West African region?

3) How did the action of the W.H.O. impact on the severity of the outbreak?

4) How did the non-action of the Western and Asian affluent countries impact the spread of the disease?

\section{Lack of Unified Healthcare Policy/Research in the West African Region}

The information on national health policy backed by substantive, measurable status on program implementation is largely absent (COHRED, n.d.) [4]. There is supposedly a structured setup to ensure that national health policy of each of the member is brought together to formulate a central policy that will guide the region. Article III, Paragraph I 1987 Protocol of WAHO states:

The objective of the West African Health Organisation shall be the attainment of the highest possible standard and protection of health of the peoples in the sub-region through the harmonisation of the policies of the Member States, pooling of resources, and cooperation with one another and with others for a collective and strategic combat against the health problems of the sub-region [5] (West African Health Organization, 2009).

The WAHO at a glance is well equipped to address the health needs of the member countries in the region through integrated computer information sharing system, as well as an information repository for the members. It is doubtful that WAHO is efficient and/or served the members by researching the Ebola disease.

Many factors could be attributed to the paucity of effective healthcare policy both for the West African regional organization and the individual countries. These factors range from failure to provide adequate funding, lack of research institutes, absence of qualified personnel and apathy by those in the field (COHRED, n.d.) [4]. Within the region, some countries are better off than others. It is in recognition of the state of the health development, and the absence of health research institutions that the West African Health Organization (WAHO) moved to set up strong research sector to enable member countries address myriad health issues within the West African region. WAHO mindful of the above deficiency in the health sector set in motion the 2009-2013 strategic plans that will make it possible for member countries to participate in health research development (COHRED, n.d.) [5]. The idea was for member countries to strengthen "governance structures, improving capacities of research institutions and enhancing the dissemination and utilization of research results" (COHRED, 
n.d. para. 2) [4].

To develop a better effective health research opportunity for the West African region, the Canadian International Development Research Centre (IDRC) gave material support to WAHO and COHRED to engage in a four year study (2011-2014). The study will enhance the ability of the selected countries "Guinea Bissau, Liberia, Mali and Sierra Leone” COHRED, n.d., para. 3) [4], to operate health care research facilities that will assist them to address myriad health issues such as Ebola. Ironically, two of the selected countries that participated in the study (Liberia and Sierra Leone) are currently suffering the brunt of the Ebola infection and deaths.

Apart from further potential degradation of the already ineffectual and underdeveloped health care system of both countries, the consequences are equally grave for their socio-economic wellbeing. For example, the Liberia government had imposed what may be termed as adverse measure in order to contain the spread of the disease through quarantine of some townships. The President of Liberia, Johnson Sirleaf said that the Liberians are concerned that the quarantine measure will rob them of their livelihood (Hinshaw, 2014) [6]. Several international and regional airline companies have refused to fly to severely affected countries such as Liberia, Sierra Leone, and Guinea (Associated Press, 2014) [7]. The airlines have not rescinded their decisions despite appeal to do so by Dr. Aylward, the WHO's assistant director-general. Dr. Aylward argued that the action of the airlines would be counter-intuitive in managing the spread of the infection (Associated Press, 2014) [7]. Beyond Liberia and Sierra Leone the rest of the countries in the West African region are likely to get caught in the web of infection cycle if one puts into consideration the projected 20000 cases by the United Nations before the disease stabilizes (Associated Press, 2014) [7].

\section{Lack of Foresight in Anticipating Potential Epidemic}

The uncontrolled Ebola outbreak could have gained currency due to the absence of strong, unified regional health policy and research regime. That notwithstanding, the failure to detect the outbreak on time and employ preventive mechanism to protect the citizens is a serious lapse on the regional policy formulation and implementation regime. There had been an intermittent outbreak of Ebola outbreaks in Africa since 1976, although, not in West Africa (Giovanni \& Germano, 1997) [1], there was no indication that WAHO or countries in the West African region had enacted actionable policy preparatory to potential Ebola outbreak.

The West African region represented by WAHO or individual countries need not formulate policy to counter Ebola outbreak from the scratch since there were data already with various international agencies such as World Health Organization, Center for Disease Control (CDC) in Atlanta etc., on the previous outbreaks. The synergic cooperation between countries and the high mobile nature of modern people makes it highly imperative that nations within a sphere of potential disease outbreak must have contingency to counter or contain it. That fact makes it more crucial considering that the cure for a disease like Ebola fever has not been discovered. The outbreak of severe acute respiratory syndrome (SARS) was first reported February 2003 (Centers for Disease Control and Prevention, 2013) [8]. SARS that was more contagious than Ebola resulted in over 8000 cases to individuals from over 30 countries, including about 750 fatalities (PubMed Health, 2013) [9].

The CDC (2013) [9] maintained that SARS infection has not been reported in any part of the world since the last case was treated. Such success in containing the SARS may be attributed to the advanced medical technology and public health policies of most of the affected countries, which equally helped in proper surveillance and management of the disease. The medical/healthcare advancement of countries in West Africa is not anywhere near the level of those of China, Europe, and United States. Their success in containing the spread of the disease could have been attributed to the fact that most of the affected countries are very affluent. Fink (2014) reported that very rich individuals had donated hundreds of millions of dollars to W.H.O. during the SARS outbreak [10]. Majority of the countries that made up the West African region are among the poorest nations in the world with population living on or below two dollars per day, and more than over 50\% survive below the poverty level line (Central Intelligence Agency, 2012 [11]; World Bank, 2012) [12]. The preceding data showed that the West African region is not prepared, and may not have been in a position to support robust surveillance without adequate funds allocated to Ebola.

\section{Lack of Modern Research Facilities/Poor Institutional Support}

The collaboration between WAHO and COHRED in partnership with the Canadian International Development Research Centre (IDRC) indicated that the WAHO did not operationalize the research institutions as intended 
for the region. The countries that participated in the study did not adapt, or were unable to utilize whatever outcome that COHRED claimed the participating countries gained from the study (COHRED, n.d.) [4]. The outbreak of Ebola as shown that the countries that the aim of building strong research base for countries of West Africa did not materialize, especially when the Liberia and Sierra Leone (especially Liberia) that took part in the studies are in danger of a major health catastrophe. Grady (2014) reported that a group of scientists have used computer modelling to conclude that the outbreak still has a life of between 12 - 18 months, and the death toll may eclipse over 50,000 people [13].

It has to be considered that majority of the members of the West African region do not have the financial capabilities to sustain world-class laboratories, and, therefore, may not support the schools financially to equip their research laboratories. A country like Nigeria could probably afford to finance such an effort, but its higher education policy has always been a source of confrontation between the federal government and the academic staff union of the university (ASUU) (Soriwei, 2013) [14]. The fallout from not having well equipped laboratories is that the universities were in no position to mobilize the Ebola experts from the various institutions to assist in the fight against the outbreaks in Liberia, Sierra Leone and Guinea.

The lack of investment in the universities' research facilities within the West African region led to the absence of well-trained Ebola experts that would have participated in blunting the infection rate. The outcome had been continuing rapid infections and death. The death from Ebola has been especially very catastrophic to the health workers who fought to save the lives of infected victims of the disease. Apart from the lack of Ebola experts in the geographical zone, the W.H.O. acknowledged that it has only one Ebola expert for Africa when the disease broke out in Guinea (Fink, 2014) [10].

\section{Lack of Purposeful Leadership in Some of the Affected Countries}

The other countries (Nigeria and Senegal) that suffered the Ebola infection took sufficient measures to contain the spread. Nigeria evidently showed a great sense of purpose from the onset of the detection of the disease through a Liberian American, who was on transit en route to United States. Nigeria has successfully contained the disease according to report credited to the Health Minister (Chukwu, 2014, This Day) [15]. President Jonathan and his Health Minister worked hard to keep the people informed by the disease, and what the government is doing at all times (Chukwu, 2014) [15], which may have accounted for the effective control.

There is no way to claim that Nigeria's health system thrives as it ought to, but the federal government and other tiers of government recognized the danger if the disease was allowed to fester. Nigeria dispatched health workers at the ports of entry into the country with thermometer to check the health status of those coming into the country (Muhumuza, 2014) [16]. The governments of Liberia and Sierra Leone failed to tackle the outbreak of the Ebola with the kind of vigor necessary to blunt the spread of the disease. They failed to convey to the people the urgency and the danger of mass exposure to the disease by the citizens. The President of Liberia was accused of neglecting those admitted in the hospitals that were left without food to starve, including those who were quarantined by the government (Ohlheiser, 2014) [17]. The type of leadership shown by the CDC in Atlanta by furnishing the necessary information to university students in United States, and the entire population with respect to infection mode, and the precautionary measure everybody should take, reduces the tendency for misunderstanding (Gov Management Daily, 2014) [18].

\section{Lack of Experience}

The knowledge of how countries outside the West African region managed the previous outbreaks was not adopted by Liberia and Sierra Leone. For example, at the outbreak of the current Ebola crisis, Uganda that had been hit by Ebola outbreak in the past took remedial action to make sure the disease did not spread in the country (Muhumuza, 2014) [16]. Ugandan health workers prepared adequate contingency by setting up quarantine facility for any individual that may be infected or who may have exhibited the symptom, as well as surveillance at the airport to screen for the ailment (Muhumuza, 2014) [16].

The same could not be said for Sierra Leone. Senegal that had a minor outbreak, quickly took action including closing of its borders with the affected countries in order to stop the escalation of the infection. W.H.O rejected Senegal's approach of closing their border with affected countries as being counterproductive. The consequence is that a country like Liberia is facing an existential problem that may lead to socio-economic collapse (Ohlheiser, 2014) [17]. The institutions of the state may fail as a result of the current crisis; perhaps the law and order 
may suffer irreparable damage as people have begun to ignore government directives.

\section{Lack of Trust}

The weak leadership exhibited by most of the countries affected by the disease engendered lack of trust between the government and the citizens. The government did not enlist the community leaders and perhaps the churches from the outset to help communicate information about Ebola without panicking them. The mistrust reached a crisis proportion in Liberia when mob raided quarantine center, thus exposing themselves even further (Fink, 2014). According to (Onishi, 2014) it took Dr. Fallah a Harvard-trained epidemiologist and immunologist to begin to win the trust of the people in the worst affected area [19]. Onishi wrote that even though Dr. Fallah is in the medical field, he was a product of the Liberian slum that the affected community could identify with him. Dr. Fallah reiterated the importance of trust thus: "If people don't trust you, they can hide a body, and you'll never know" (Onishi, 2014, para 7) [19].

\section{The W.H.O. Budget Cut}

The W.H.O. budget cut impacted its ability to react to the Ebola outbreak in the West African region (Fink, 2014) [10]. The agency's budget was slashed by $\$ 1$ billion down to $\$ 3.98$ billion despite the fact that the agency's burden has increased with crises from Syrian conflicts, Europe, and Africa (Fink, 2014) [10]. W.H.O's budget is a paltry sum compared to CDC budget of $\$ 6.6$ billion (CDC, 2014) [20]. The impact of W.H.O's budget cut was probably the critical element that undermined the ability to quell the spread of the infection. Fink (2014) wrote issues that emanated from the effect of the budget cut shows:

1) Exposed how rapidly infection like Ebola can spread due to the nature of our interconnected world

2) The operations of W.H.O. "outbreak and emergency response units have been slashed” (Fink, 2014) which caused a lot of old employees with experience to leave the agency

3) The disease was not reported on time because the job of detection was left for the poor countries that lacked the resources and probably short on expertise

4) W.H.O. may have underestimated the scope of the Ebola spread because the agency was accused of lacking strategy to contain the outbreak

5) W.H.O., prioritize where to put scarce resources. W.H.O. deep budget cut means that donors to the agency often dictate where they spend the money

6) Allocation of staff by W.H.O. to pandemic and hemorrhagic diseases was down to below 60 people with one technical expert on Ebola

7) Veteran staff of Ebola crises in Africa were cut down to three [10]

Other contributing factors to the spread of Ebola crisis were the inability of the hospitals in the affected countries to procure basic accessories to prevent infections such as gloves, running water, and protective gowns. Dr. Simon Mardel, a British emergency doctor with W.H.O. claimed that less than $10 \%$ of Ebola cases in West Africa were being followed unlike in the previous episodes (Fink, 2014) [10]. A team of researchers led by Dr. Shaman projected that the current Ebola cases will eclipse over 50,000 before it could be contained and brought under control (Grady, 2014) [13]. This projection must have been informed on the inability of most of the affected countries to control the rapid spread of the virus. Apart from the absence of equipment and chemicals for the local health workers, they were also not paid. No one could predict exactly how the non-remuneration affected the spread of Ebola in the affected countries.

\section{Lack of Attention by the Rich Nations}

Countries like United States, Britain, France, China, Japan, and Germany ignored the scourge of the Ebola crisis in the West African region. The intensity with which the western countries and China fought the SARS and H1N1 outbreak was remarkable. Fink (2014) reported that affluent individuals donated large sums of money to the W.H.O. to ensure that the diseases were contained [10]. The Ebola outbreak in West Africa had been known to these countries at least since March of 2014 when CDC reported it [20]. Even when some of the western nations give relief, it was not coordinated, and there was a suggestion that former colonial countries concentrated aid to their former colonies. Finally, several commenters argued that it took the infection of white American missionary doctors for the United States through President Obama to announce the major Ebola initiative (The 
WHITE HOUSE, 2014) [21].

\section{Conclusions}

The Ebola outbreak that is ongoing in the West African region could not have been so severe if some basic precaution were taken by the people and the governments. It was imperative to note that Ebola disease was alien to the people in the West African region, and the outbreak took place in a rural area where ignorance of the disease's symptom must have been a factor in the sustained infection spread and fatalities. The bureaucratic inertia in the severely affected countries may have led to the exacerbation of the Ebola infection. The inability of the affected governments to communicate to their citizens the proper preventive measures created atmosphere of fear and mistrust.

There is also a known fact that most of the affected countries are among the poorest countries in the world that lack necessary public health infrastructure to combat the outbreak. These affected countries lack the financial resources as well as the trained experts in Ebola disease to deploy to contain the disease. It is also incontrovertible that the W.H.O. budget cut affect many aspects of the disease management, which include proper surveillance, inability to retain robust staff and experts who know about Ebola treatment and containment. The lack of concern by the affluent countries to the ravages of Ebola in the West African region contributed immensely to the wild spread of the disease.

\section{Recommendations}

Collaboration between the affected countries and the W.H.O. should be a constant between them and other countries in the West African region. This is to help them keep up with the development with Ebola disease so that they can be better equipped when confronted with another outbreak. The investment in the public health is shown to be inadequate to cope with the outbreak; therefore countries in the region must do a better job to invest in this critical sector. The alternative to the lack of investment in the public health sector may be the current abandonment of the affected countries by airlines, business and people traffic.

Countries like United States and China pledged to help, with United States planning to develop massive infrastructure in Liberia, China in Sierra-Leone. So what happens after the disease has been controlled? The affected countries would need to maintain the facilities they will inherit. It is important that they solicit for assistance from the donor countries for continued training of local personnel to take over the facilities. It will be unwise for the donor countries to leave prematurely, and these assets fall to disuse and disrepair. The affluent countries should consider early interventions to the outbreak of diseases such as Ebola, as not only contributing to the positive social change, but also wise health policy to protect their citizens. In a synchronized world, it is easy for disease to spread across the globe. Finally, the W.H.O. should make it a priority to hire adequate experts knowledgeable in Ebola virus, but will be more economically beneficial if W.H.O. would hire the experts from the area of proximity to the Ebola outbreaks.

\section{References}

[1] Giovanni, A.C. and Germano, M. (1997) Health Status and Health Policy in Sub-Saharan Africa: A Long-Term Perspective. The United Nations University World Institute for Development Economics Research (UNU/WIDER).

[2] Waterman, T. (1999) Brief General History of Ebola. Honors Thesis Stanford University. https://web.stanford.edu/group/virus/filo/history.html

[3] Avert (2012) Africa HIV and AIDS Statistics 2011. http://www.avert.org/africa-hiv-aids statistics.html

[4] COHRED (n.d.) Strengthening Research System Development for Health in West Africa. Council on Health Research for Development. Except. http://www.cohred.org/westafrica/

[5] West African Health Organization (2009) About WAHO: History and Mission. http://www.wahooas.org/spip.php?page=rubriqueS\&id rubrique=24\&lang=en

[6] Hinshaw, D. (2014) Ebola Virus Outbreak Tests Liberian President. President Johnson Sirleaf: "Unlikely We Are Yet at the Peak of Ebola's Spread”. The Wall Street Journal. http://online.wsj.com/articles/liberia-struggles-to-contain-ebola-virus-outbreak-1409062213

[7] Associated Press (2014) U.N. Says Ebola Cases Could Eventually Reach 20000. http://krqe.com/2014/08/28/un-ebola-cases-could-eventually-reach-20000/ 
[8] Centers for Disease Control and Prevention (2013) Severe Acute Respiratory Syndrome (SARS) CDC. http://www.cdc.gov/sars/

[9] PubMed Health (2013) Severe Acute Respiratory Syndrome (SARS). A.D.A.M. Encyclopedia. http://www.ncbi.nlm.nih.gov/pubmedhealth/PMH0004460/

[10] Fink, S. (2014) Cuts at W.H.O. Hurt Response to Ebola Crisis. The New York Times. http://www.nytimes.com/2014/09/04/world/africa/cuts-at-who-hurt-response-to-ebola-crisis.html?emc=edit_th_201409 04\&nl=todaysheadlines\&nlid=36347621

[11] Central Intelligence Agency (2012) Population below Poverty Line. The World Fact Book.ooks. https://www.cia.gov/library/publications/the-world-factbook/fields/2046.html

[12] The World Bank (2012) The World Development Indicators. http://data.worldbank.org/sites/default/files/wdi-2012-ebook.pdf

[13] Grady, D. (2014) US Scientists See Long Fight against Ebola. The New York Times. http://www.nytimes.com/2014/09/13/world/africa/us-scientists-see-long-fight-against-ebola.html?emc=edit_th_201409 $13 \&$ nl=todaysheadlines\&nlid=36347621

[14] Soriwei, P. (2013) NLC, TUC to Mediate in FG, ASUU Dispute. Punch. http://www.punchng.com/news/nlc-tuc-to-mediate-in-fg-asuu-dispute/

[15] Chukwu, O. (2014) Health Minister: Nigeria Now Has One Active Ebola Case. ThisDay Liv. http://www.thisdaylive.com/articles/health-minister-nigeria-now-has-one-active-ebola-case/187449/

[16] Muhumuza, R. (2014) Lack of Experience Fuels West Africa Ebola. Associated Press. http://healthyliving.msn.com/health-wellness/lack-of-experience-fuels-west-africa-ebola-crisis

[17] Ohlheiser, A. (2014) Ebola Is “Devouring Everything in Its Path”. Could It Lead to Liberia’s Collapse? The Washington Post. http://www.washingtonpost.com/news/to-your-health/wp/2014/09/11/ebola-is-devouring-everything-in-its-path-could-i t-lead-to-liberias-collapse/

[18] Gov Management Daily (2014) Take Ebola Precautions, CDC Warns Colleges. Management in the Public Sector: News, Analysis and More in Partnership with American Society for Public Administration. http://www.nytimes.com/2014/09/03/health/us-colleges-advised-to-tighten-ebola-precautions.html?_r=0\&gwh=38FCA C67F8B33CB1DDF430D57F8E2283\&gwt=pay\&assetType=nyt_now

[19] Onishi, N. (2014) Back to the Slums of His Youth, to Defuse the Ebola Time Bomb. The New York Times. http://www.nytimes.com/2014/09/14/world/africa/ebola-liberia.html?emc=edit_th_20140914\&nl=todaysheadlines\&nli $\mathrm{d}=36347621$

[20] Centers for Disease Control and Prevention (2014) Budget Request Summary-Fiscal Year 2014. CDC. http://www.cdc.gov/fmo/topic/Budget\%20Information/appropriations_budget_form_pdf/FY2014_Budget_Request_Su mmary.pdf

[21] The WHITE HOUSE (2014) Remarks by the President on the Ebola Outbreak. The WHITE HOUSE: Office of the Press Secretary. http://www.whitehouse.gov/the-press-office/2014/09/16/remarks-president-ebola-outbreak 
Scientific Research Publishing (SCIRP) is one of the largest Open Access journal publishers. It is currently publishing more than 200 open access, online, peer-reviewed journals covering a wide range of academic disciplines. SCIRP serves the worldwide academic communities and contributes to the progress and application of science with its publication.

Other selected journals from SCIRP are listed as below. Submit your manuscript to us via either submit@scirp.org or Online Submission Portal.
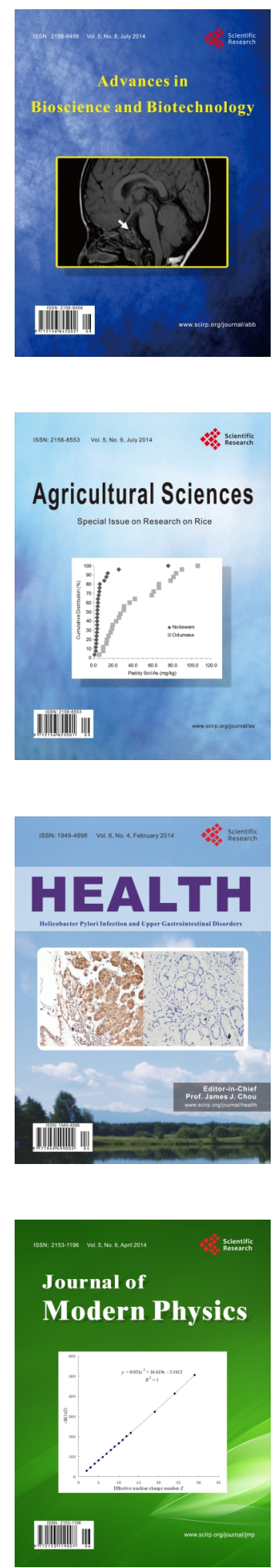
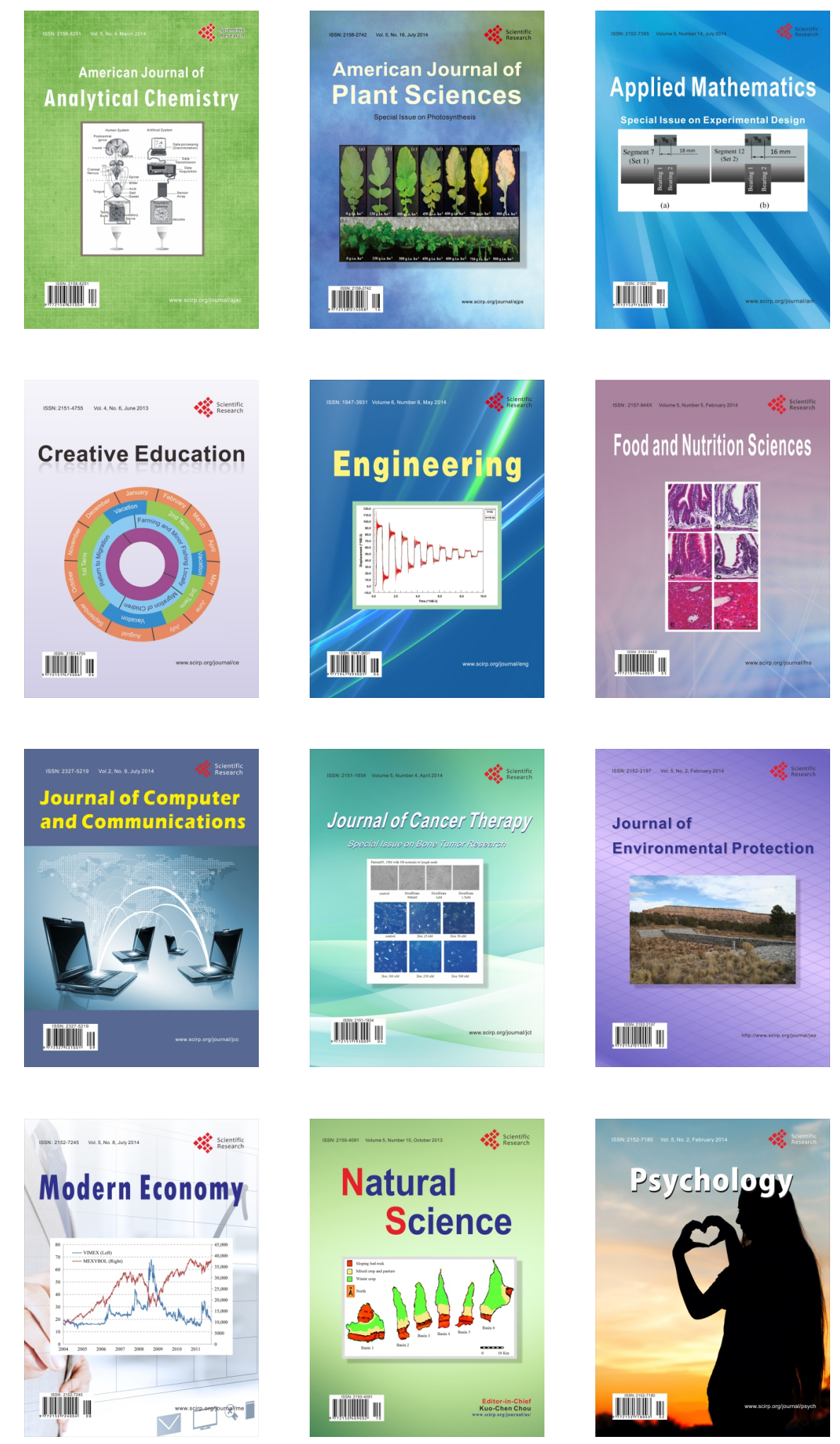